\title{
Carcinoma adenoide quístico en conducto auditivo externo, a propósito de un caso
}

\author{
- Juanita Martínez, Einstein Viana, Sandra Aruachán
}

IMAT Oncomédica (Montería)

Introducción: el carcinoma adenoide quístico del conducto auditivo externo es un tumor extremadamente raro, su crecimiento es silente, con alta probabilidad de invasión perineural, metástasis y recurrencia locorregional, debido a su difícil resección completa por la complejidad del área anatómica.

Materiales y métodos: se presenta el caso de una paciente de 73 años de edad con cuadro de 10 años de evolución de otalgia y prurito en oído derecho; al examen físico presenta lesión que compromete conducto auditivo externo y lo ocluye, impidiendo la valoración de oído medio e interno; se realizan estudios complementarios, identificando lesión en conducto auditivo externo que oblitera casi la totalidad de este, sin extensión ósea.

Resultados: se tomó biopsia de la lesión, evidenciando carcinoma adenoide quístico, T2, N0, M0, por lo cual se lleva a resección oncológica de conducto auditivo externo, mastoidectomía derecha, reconstrucción con colgajo de temporal para cobertura de mastoides, con reporte patológico de compromiso de margen profundo. Por esto, se hace ampliación de márgenes que incluye pabellón auricular, conducto auditivo externo, medio y membrana timpánica, mastoidectomía, timpanoplastia con cartílago de concha auricular y reconstrucción de neoconducto con doble colgajo, con excelentes resultados cosméticos y funcionales.

Conclusiones: el tratamiento de elección es la mastoidectomía con márgenes para evitar la invasión perineural, ósea y las recurrencias locales. Algunos autores recomiendan radioterapia en estadios avanzados. En el presente caso se efectuó tratamiento quirúrgico con radioterapia adyuvante, el posoperatorio transcurrió sin complicaciones. 